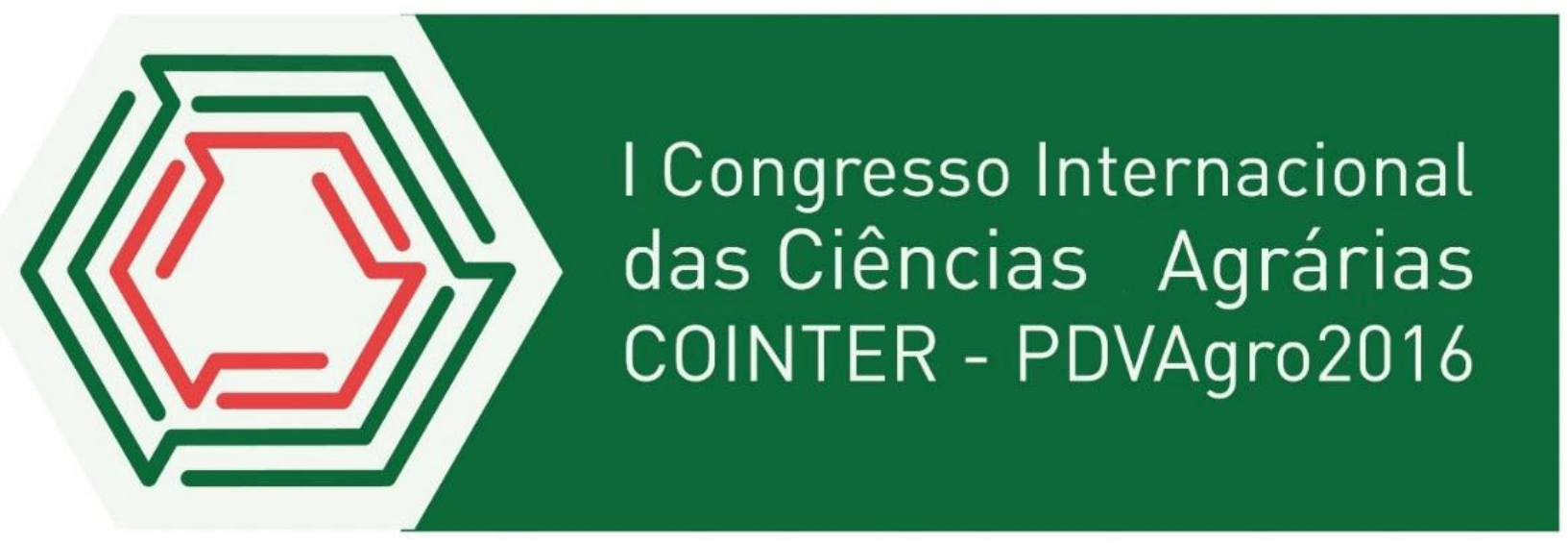

\title{
ANÁLISE DAS BOAS PRÁTICAS DE FABRICAÇÃO (BPF): APLICAÇÃO DE UM CHECK-LIST EM DOIS FRIGORÍFICOS NO MUNICÍPIO DE SALGUEIRO-PE.
}

\author{
Apresentação: Pôster \\ Gabriela Araujo de Oliveira Maia ${ }^{1}$; Clemilson Elpidio da Silva ${ }^{2}$; Djalma Vitorino Costa \\ filho $^{2}$; Iolanda Severo de Lima ${ }^{4}$ Luciana Façanha Marque ${ }^{5}$.
}

\section{INTRODUÇÃ̃o}

As Boas Práticas de Fabricação (BPF) são um conjunto de normas empregadas em produtos, processos, serviços e edificações, visando a promoção e a certificação da qualidade e da segurança do alimento. No Brasil, as BPF são legalmente regidas pelas Portarias 1428/93-MS [5] e 326/97SVS/MS [7]. A qualidade da matéria-prima, a arquitetura dos equipamentos e das instalações, as condições higiênicas do ambiente de trabalho, as técnicas de manipulação dos alimentos, a saúde dos funcionários são fatores importantes a serem considerados na produção de alimentos seguros e de qualidade, devendo, portanto, serem considerados nas BPF.

A demanda da produção de alimentos de origem animal tem aumentado proporcionalmente com o escoamento dos produtos dos mercados consumidores. Para que estes produtos cheguem ao

\footnotetext{
${ }^{1}$ Tecnologia em alimentos, Instituto Federal de Educação, Ciência e Tecnologia do Sertão Pernambucano - Campus salgueiro, gabryella_maia@ @otmail.com

${ }^{2}$ Tecnologia em alimentos, Instituto Federal de Educação, Ciência e Tecnologia do Sertão Pernambucano - Campus salgueiro. clemilsonelpidio@gmail.com

${ }^{3}$ Tecnologia em alimentos, Instituto Federal de Educação, Ciência e Tecnologia do Sertão Pernambucano - Campus salgueiro.Djalma.viturino@vitoria.ifpe.edu.br

${ }^{4}$ Tecnologia em alimentos, Instituto Federal de Educação, Ciência e Tecnologia do Sertão Pernambucano - Campus salgueiro. Iolanda.sl@ hotmail.com

${ }^{5}$ Profa. Dra. Instituto Federal de Educação, Ciência e Tecnologia do Sertão Pernambucano - Campus salgueiro. marques.luciana@gmail.com
} 
consumidor final com suas características físicas, químicas e microbiológicas dentro dos padrões higiênico-Sanitários, é primordial a utilização da cadeia de frio que compreende desde a produção, estocagem, o transporte e a distribuição dos alimentos (BERNARDES, 2010)

Entre os objetivos da Gestão da qualidade se destacam o desenvolvimento dos colaboradores a autodisciplina e sua participação na busca por melhorias no sistema produtivo, com enfoque na qualidade dos alimentos (OPRIME; MENDES; PIMENTA, 2011).

\section{FUNDAMENTAÇÃO TEÓRICA}

Segundo a Associação Brasileira das Indústrias de Alimentação - ABIA (2015), as vendas da indústria para o setor avançaram 12,4\% no primeiro semestre deste ano, em comparação ao mesmo período de 2014 - ano em que o segmento registrou alta de 13,6\% e faturou R $\$ 132,5$ bilhões. Para a Associação Brasileira de Empresas de Refeições Coletivas - ABERC (2015), a estimativa do número de refeições a serem servidas para o ano de 2015, é 12,6 milhões de refeições/dia.

A necessidade de estabelecer critérios e práticas norteando a qualidade nos serviços de alimentação, fez a Agência Nacional de Vigilância Sanitária - ANVISA, estabelecer no ano de 2002 e 2004, respectivamente, a Resolução de Diretoria Colegiada n 275 de 21 de outubro de 2002, que dispõe o Regulamento Técnico de Procedimentos Operacionais Padronizados aplicados aos Estabelecimentos Produtores/Industrializadores de Alimentos e a Lista de Verificação das Boas Práticas de Fabricação em Estabelecimentos Produtores/Industrializadores de Alimentos (BRASIL, 2002) e a Resolução de Diretoria Colegiada no 216 de 15 de setembro de 2004, que dispõe o Regulamento Técnico de Boas Práticas para Serviços de Alimentação (BRASIL, 2004).

\section{METODOLOGIA}

Trata-se de um método de pesquisa Qualitativa, Quantitativa com avaliação experimental descritiva. Para a realização da coleta de dados e, posteriormente, para o diagnóstico, foi utilizada a técnica de pesquisa de estudo de campo caracterizado pela formulação da maioria das perguntas previstas e elaboradas antecipadamente.

Para a sua execução foi realizada a aplicação de uma lista de verificação (check-list) adaptado a partir da Lista de Verificação de Boas Práticas de Fabricação em estabelecimentos Produtores/ Industrializados de alimentos da $\operatorname{RDC}^{\circ}$ 275, de 21 de Outubro de 2002 da Agência Nacional de 
Vigilância Sanitária (BRASIL, 2002) para os setores pesquisados. Foram observados os itens: Edificação e Instalações; Equipamentos, móveis e utensílios, Manipuladores; Produção e Transporte de Alimentos e documentação.

\subsection{Edificação e Instalações}

Verificou-se a área externa, acesso, área interna, piso, teto, paredes e divisórias, portas e janelas, instalações sanitárias para funcionários e visitantes, lavatórios, iluminação e rede elétrica, ventilação, climatização e higienização, controle integrado de pragas, abastecimento de água, manejo de resíduos, esgotamento sanitário e leiaute.

\subsection{Equipamentos, móveis e utensílios}

Verificou-se equipamentos da linha de produção bem como seu estado de conservação, contato da superfície com o alimento e o estado de conservação e funcionamento.

\subsection{Manipuladores}

Observou-se vestiários, hábitos higiênicos, estado de saúde, programa de controle de saúde, uso de EPI's, programas de capacitação e supervisão.

\subsection{Produção e Transporte do Alimento}

Foram avaliados matéria-prima, ingredientes e embalagens, fluxo de produção, rotulagem e armazenamento, controle de qualidade e transporte do produto final.

\subsection{Documentação}

Analisou-se manual de boas práticas, procedimento operacional padronizado e programas de auto controle.

\section{Resultados E Discussões}

Dos 163 itens avaliados, como pode-se observar no Gráfico 1, constatou-se $82 \%$ de SIM, $10 \%$ de NÃO e $19 \%$ de NÃO SE APLICA. De acordo com os resultados expostos o frigorífico de 
Suínos, fica classificado o Grupo II, pois apresenta $82 \%$ de itens em conformidade, no Gráfico 2, constatou-se 76\% SIM, 20\% NÃO e 4\% de NÃO SE APLICA. Conforme o Gráfico II os resultados do frigorífico de bovinos está classificado também no Grupo II, pois apresenta $76 \%$ de conformidade. Esses fatos podem ser considerados razoáveis, pois precisam de poucas adequações.

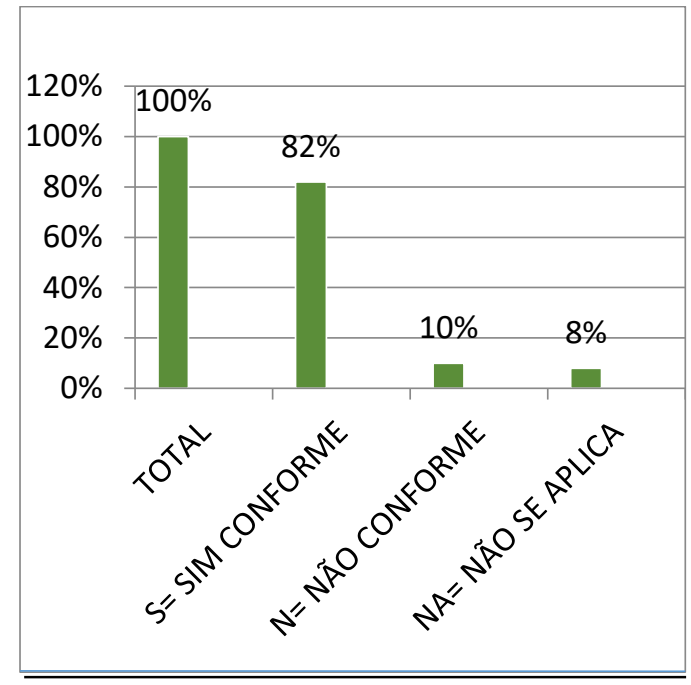

Gráfico 1: Resultado geral do check list, aplicado em frigorífico de suínos.

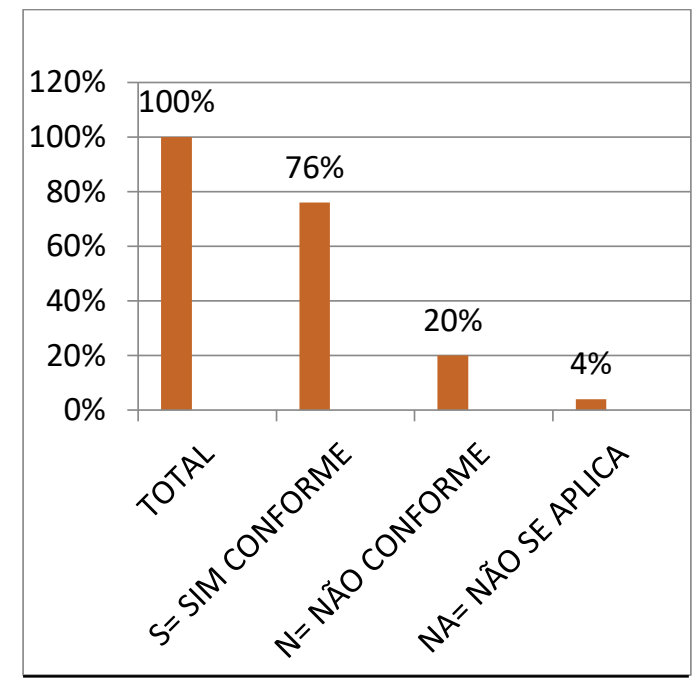

Gráfico 2: Resultado geral do check list, aplicado em frigorífico de bovinos

$\mathrm{O}$ check list aplicado foi formado de diversos questionamentos, divididos em 5 eixos. Onde cada eixo era composto de três possibilidades de resposta: SIM, NÂO OU NÂO SE APLICA. Os resultados dos itens avaliados, por eixo, da lista de verificação, estão apresentados na tabela 1 e 2 .

Tabela 1: Check list para avaliação em frigorífico de suínos

\begin{tabular}{|c|c|c|c|c|c|c|c|}
\hline EIXO & ITENS & SIM & $\%$ & NÃO & $\%$ & NA & $\%$ \\
\hline Edificações e Instalações & 78 & 62 & $79 \%$ & 13 & $16 \%$ & 4 & $5 \%$ \\
\hline $\begin{array}{l}\text { Equipamentos, Móveis e } \\
\text { Utensílios }\end{array}$ & 21 & 21 & $100 \%$ & 0 & & 0 & \\
\hline Manipuladores & 13 & 9 & $69 \%$ & 3 & $23 \%$ & 1 & $8 \%$ \\
\hline $\begin{array}{l}\text { Produtos e transporte do } \\
\text { alimento }\end{array}$ & 33 & 23 & $70 \%$ & 0 & & 10 & $30 \%$ \\
\hline Documentação & 18 & 18 & $100 \%$ & 0 & & 0 & \\
\hline
\end{tabular}

Tabela 2: Check list para avaliação de frigorífico de bovinos

\begin{tabular}{lllcccrr}
\hline EIXO & ITENS & SIM & \% & NÃO & \% & NA & \% \\
\hline Edificações e Instalações & 78 & 53 & $68 \%$ & 21 & $27 \%$ & 4 & $5 \%$
\end{tabular}




\begin{tabular}{lrrrrrr}
$\begin{array}{l}\text { Equipamentos, Móveis } \\
\text { Utensílios }\end{array}$ & 2 & 18 & $90 \%$ & 2 & $10 \%$ & 0 \\
$\begin{array}{l}\text { Manipuladores } \\
\text { Produtos e transporte do }\end{array}$ & 13 & 11 & $78 \%$ & 3 & $22 \%$ & 0 \\
$\begin{array}{l}\text { alimento } \\
\text { Documentação }\end{array}$ & 18 & 29 & $87 \%$ & 1 & $3 \%$ & 3 \\
\hline
\end{tabular}

Com estes resultados o estabelecimento encontra-se no grupo II, seguindo a tabela da resolução RDC 27512002 da ANVISA. Diante destes resultados foi proposto um plano de ação visando mudanças e melhorias.

\section{Conclusões}

Após a realização do diagnóstico nos frigorífico, foi possível constatar que as empresas classificam-se no grupo II. Neste sentido, ainda há espaço de melhorias através de uma fiscalização mais rígida, pois se observa falta de comprometimento ou falta de conhecimento nos requisitos higiênico sanitários e qualidade.

\section{Referências Bibliográficas}

ANVISA - Ministério da Saúde. Agência Nacional de Vigilância Sanitária. Resolução RDC N ${ }^{\circ} 275$, de 21 de outubro de 2002.

ASSOCIAÇÃO BRASILEIRA DAS INDÚSTRIAS DE ALIMENTAÇÃO - ABIA - ABIA debateu sobre tendências e inovação no $8^{\circ}$ Congresso Internacional de Food Service, 2015. Disponível em: http://www.abia.org.br/vs/vs_conteudo.aspx?id=298. Acesso em: 29 de outubro de 2015.

BRASIL. Ministério da Saúde. Agência Nacional de Vigilância Sanitária (ANVISA). Resolução RDC n. 216, de 15 de setembro de 2004. Dispõe sobre o regulamento técnico de boas práticas para serviços de alimentação. Disponível em: http://www.anvisa.gov.br/. Acesso em: 07 de novembro de 2015.

BRASIL. Circular N. 176 de 16 de maio de 2005. Modificação das Instruções para a verificação do PPHO, encaminhados pela Circular N 201/97 DCI/DIPOA e aplicação dos procedimentos de verificação dos Elementos de Inspeção previstos na Circular No 175/2005 CGPE/DIPOA.

OPRIME, P,C. MENDES, G.H.S.; PIMENTA, M.L. Fatores Críticos para a Melhoria Contínua em Abatedouros Brasileiras. Produção, v.21, n,1, p 1-13, jan/mar 2011. 
SILVA, A. V.; SILVA, K. R. A.; BESERRA, M. L. S. Conhecimentos do controle higiênico-sanitário na manipulação de alimentos em domicílios: revisão bibliográfica. Nutri Gerais. v. 6, n. 10. p. 918932 fev./jul. 2012. 